\title{
43. LOS GÉNEROS THRINCIA ROTH Y LEONTODON L. (COMPOSITAE, CICHORIEAE) EN FLORA IBERICA
}

\author{
Salvador TALAVERA*, María TALAVERA y Carlos SÁNCHEZ
}

Recibido el 21 de octubre de 2015, aceptado para su publicación el 15 de noviembre de 2015

The genus Thrincia Roth and Leontodon L. (Asteraceae, Cichorieae) in Flora Iberica

Palabras clave. nomenclatura, diversidad, corología, Región Mediterránea, nuevos táxones, tipificación.

Key Words. nomenclature, diversity, chorology, Mediterranean basin, new records, typification.

El género Thrincia ha estado reconocido por la mayoría de los botánicos del siglo XIX. Solo en el siglo XX, casi de forma general, las especies de este género se incluyeron en Leontodon, quizás debido al tipo de indumento, que en ambos géneros es semejante, pero la organización del involucro y de los aquenios es muy diferente.

El involucro de Leontodon es multiseriado, con brácteas externas, medias e internas, las medias de más de la mitad de la longitud que las internas, mientras que en en el génro Thrincia el involucro carece de brácteas medias, y tiene solo brácteas complementarias en la base del involucro, por lo general menores de un tercio de la longitud de las internas. Los aquenios en Leontodon son homomorfos o subhomomorfos, todos los del capítulo \pm iguales y con vilano plumoso bien desarrollado, mientras que en Thrincia son dimorfos, los más externos del capítulo son por lo general poligonales y con vilano formado por una corona de escamas \pm soldadas entre sí, y los internos son casi siempre fusiformes y con el vilano formado de escamas setiformes aplanadas en la base, libres entre sí o solo soldadas en la base, todas plumosas, o las más externas escábridas y bastante más cortas que las internas.

Estudios filogenéticos han mostrado que el género Thrincia forma un grupo monofilético, no incluido en el núcleo del género Leontodon (Enke et al., 2012). A pesar de las diferencias morfológicas y genéticas, se conocen híbridos estériles en el norte de Europa entre Thrincia saxatilis y Leontodon hispidus (Finch, 1967).

En este trabajo se avanza el conocimiento taxonómico de los géneros Thrincia y Leontodon en el ámbito de la Flora iberica, indicando para cada uno de ellos los taxones que comprende y una clave para la identificación de sus especies, así como datos sobre su ecología y distribución, y en muchos casos sobre tipificación de los táxones.

Thrincia Roth in Arch. Bot. (Leipzig) 1: 36 (1796)

= Colobium Roth in Arch. Bot. (Leipzig) 1: 36 (1796)

Especie tipo (tipificado aquí): Colobium hirtum Roth in Arch. Bot. (Leipzig) 1: 38 (1796), = Thincia saxatilis (Lam.) Holub \&

Este trabajo ha sido financiado por el proyecto Flora iberica (CGL2012-32914) y cofinanciado con fondos FEDER 
Moravec.

Hierbas anuales, bienales o perennes, caulescentes, escaposas, glabras o pelosas, \pm estrigosas, con indumento formado por pelos \pm pediculados 2-4-fidos, a veces junto a pelos simples e indivisos en tallos, hojas y en el dorso de las brácteas del involucro, a veces también con pelos subestrellados en el margen y dorso de las brácteas; raíz axonomorfa, delgada o algo gruesa, o con rizoma vertical u horizontal, el vertical corto, con raíces finas o tuberificadas formando fascículos, el horizontal con 2 o más rosetas de hojas \pm distanciadas en cada ciclo reproductor. Tallos erectos, acostillados, cilíndricos, frecuentemente con mayor diámetro en el ápice, junto al capítulo, ápteros, simples, monocéfalos, excepcionalmente divaricados en la mitad inferior, con ramas monocéfalas, afilos o con 1-3 brácteas cerca del ápice, glabros o pubescentes. Hojas uninervadas, pinnatinervias, lineares, elípticas o más frecuentemente oblanceoladas, atenuadas en la base en un pecíolo ancho y alado o estrecho y áptero, enteras o dentadas, pero por lo común lobadas, pinnatífidas o pinnatisectas, a veces runcinadas o disectas, de consistencia herbácea o coriácea, glabras o glabrescentes, pero con mayor frecuencia estrigosas, verdosas o cenicientas. Capítulos solitarios, péndulos antes de la antesis, erectos en la madurez, multifloros. Involucro con 1-2 series de brácteas acompañadas de brácteas suplementarias en la base, mucho más cortas y estrechas que las internas; brácteas erectas, adpresas, planas, glabras o pelosas en el dorso, las suplementarias lineares o triangulares, herbáceas, las internas linearelípticas, obtusas, con un margen escarioso en la mitad inferior, ciliadas en el ápice, ventralmente glabras. Receptáculo alveolado, con los alvéolos de margen \pm escarioso, dentado o entero, glabros o pelosos, sobre todo los centrales del receptáculo, con los pelos mucho más cortos que los ovarios. Flores liguladas, con 5 dientes, hermafroditas, las externas del capítulo mayores que las internas. Corola con el tubo glabro o peloso y el limbo viloso en la base o en casi todo el dorso, amarilla, en las flores más externas del capítulo con una banda verdosa, azulada o rosada en el dorso del limbo. Anteras amarillas. Ramas estilares amarillentas, rosadas o negruzcas. Aquenios dimorfos, con 5 costillas longitudinales, a veces los centrales del capítulo con costillas secundarias complementarias, glabros, pardo-rojizos; los externos del capítulo dispuestos en 1-3 filas, por lo general poligonales, con o sin pico, glabros o pubérulos, con escuámulas transversales poco marcadas, con frecuencia amarillentos; los centrales por lo general fusiformes, con pico \pm desarrollado, rara vez sin pico, con escuámulas transversales \pm marcadas, a menudo también con espículos en el ápice del cuerpo y en la base del pico. Vilano blanco, pardusco o blanco-amarillento; en los aquenios externos formado por una corona escariosa, glabra o \pm pubescente, persistente; en los internos con (9)10-20 escamas aplanadas en la mitad inferior, dispuestas en 2 filas, todas plumosas, pero con frecuencia la fila más externa con las escamas escábridas, a veces muy pequeñas o incluso faltan, persistentes o caedizas. $x=8$.

\section{Observaciones}

Al género se le reconocen 8 especies, distribuidas principalmente por la Región Mediterránea, aunque algunas de ellas alcanzan el N de Europa, SW de Asia y Macaronesia.

La mayoría de sus especies se han cultivado en invernadero y se ha comprobado que se comportan como alógamas obligadas, por lo que se supone que son autoincompatibles.

Además de las especies reconocidas para Flora iberica, en los humedales del litoral Atlántico y del Atlas Medio de Marruecos vive Thrincia mesorhyncha (Maire) Pau in Font Quer, Iter Marocc. 1930: No. 726 (1930), in sched. [ $\equiv$ Leontodon nudicaulis subsp. mesorhynchus Maire in Mém. Soc. Sci. Nat. Marocc. 15: 45 (1926), basión.; $\equiv L$. 
saxatilis subsp. mesorhynchus (Maire) Maire in Jahandiez \& Maire, Cat. Pl. Maroc: 830 (1934); 三L taraxacoides subsp. mesorhynchus (Maire) Valdés in Lagascalia 18: 308 (1996)]. La especie fue descrita con material del NW de Marruecos [Ind. loc.: "Hab. In uliginosis planitiei Gharb nec non Atlantis Medii, ubi a junio usque ad augustum floret: secus amnem Fouarat prope Kenitra, ad alt. c. $10 \mathrm{~m}$; in Atlante Medio ad lacum Ouiouane, $1.600 \mathrm{~m}$, ad Ras-el Mas 1.600 m, ad lacum Sidi Ali-ou-Mohand, $2.100 \mathrm{~m}$, solo calcáreo.- Typus in Herb. Univers. Algeriensis et in Herb. Inst. Imper. Scient. Rabatensis". Lectotipo (designado aquí): Etiqueta 1. Leontodon mesorrynchum /n. sp. / sive L. Nudicaulis (L.) Banks / ssp. Mesorrynchum / Maire...... [descripción de R. Maire, idéntica a la publicada]. Etiqueta 2. UNIVERSITÉ D'ALGER / HERBIER DE L'AFRIQUE DU NORD [impresa] / Leontodon mesorrhynchum Maire / Moyen Atlas: Azrou, prairies tourbeuse s/ à Ras- elMa, calcaire 1.600 m. / 16-6-1923 /Dr. R. Maire / corolles jaune d'or (MPU-001804)]. El tipo lo constituye un rizoma con hojas de más de $10 \mathrm{~cm}$, largamente pecioladas, tres escapos fragmentados y tres capítulos, uno en flor, otro en fruto, y el tercero próximo a la antesis. Los caracteres de hojas y capítulos son coincidentes con la descripción. Por ser el único material con la descripción original escrita por Maire, y ser coincidentes los caracteres de las plantas con dicha descripción, se elige dentro del sintipo el material MPU-001804 como lectotipo. Otros materiales estudiados del sintipo son: Moyen Atlas: Aguelman Sidi Ali ou Mohand, grives sablonneuses humides-2090 m- [Maire en la publicación indica 2100] 30-VI-1923, Dr. R. Maire (MPU-001807); Moyen Atlas, lac de Ouiouane, prairies tourbeuses, $1600 \mathrm{~m}$, 23-VI-1923, Dr. R. Maire (MPU-001808)].

Thrincia mesorrhyncha es una especie estolonífera que invade prácticamente toda la superficie de los humedales en que vive. Sus hojas, que caracterizan muy bien a esta especie, son gruesas, onduladas, muy pelosas, casi seríceas, con el nervio medio ancho y blanco. Como en todas las especies de Thrincia, tiene aquenios dimorfos, los externos de 4,7-5,2 x 0,65-0,7 mm, obcónicos, glabros, con el vilano formado una corona escariosa, dentada y glabra, y los centrales de 5,2-9 x 0,6-0,7 $\mathrm{mm}$, fusiformes, con pico de 1-3 mm, con escuámulas erosas transversales poco marcadas y espículos en el ápice del cuerpo, con el vilano formado por 1 o 2 filas externas de escamas escábridas de 1-3,5 mm, y 1 fila interna con 10 escamas plumosas de 5,7-8 $\mathrm{mm}$.

\section{Clave para las especies}

1. Flores externas del capítulo con el dorso del limbo de la corola densamente viloso en casi toda su longitud, o con pelos solo en la base y en el margen del limbo; brácteas internas del involucro con pelos subestrellados muy cortos -menores de $0,1 \mathrm{~mm}$ - en el margen y a veces también en el dorso; aquenios externos del capítulo pubescentes, los centrales con el pico (2) 3 veces la longitud del cuerpo ............ 7. T.maroccana

- Flores externas del capítulo con el dorso del limbo de la corola \pm viloso solo en la mitad o en el tercio inferior; brácteas internas del involucro sin pelos subestrellados cortos, con el dorso glabro o con pelos mayores de $0,3 \mathrm{~mm}$, simples o bífidos, rara vez trífidos; aquenios externos del capítulo glabros, los centrales con el pico más corto que el cuerpo o casi de su longitud, o sin pico ......2

2. Planta perenne, por lo general con tubérculos gruesos y carnosos formando fascículos en la base del rizoma vertical; hojas a menudo runcinadas, con pecíolo largo y estrecho, a veces casi de la longitud del limbo; ramas estilares generalmente negruzcas; vilano de los aquenios internos del capítulo caedizo, con 18-20 escamas plumosas menores de $0,10 \mathrm{~mm}$ de anchura en la base 6. T. tuberosa

- Planta anual o perenne, sin tubérculos; hojas de enteras a pinnatisectas, nunca runcinadas, con el pecíolo generalmente corto y ancho, de menor longitud que el limbo; ramas estilares amarillentas; vilano de los aquenios internos del capítulo persistente, con (9)10-20 escamas plumosas de 0,05-0,30 $\mathrm{mm}$ de anchura en la

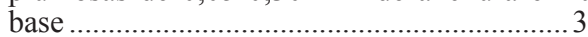

3. Aquenios centrales del capítulo con pico de 2-5 mm y vilano formado por 10 escamas plumosas, 
por lo general acompañadas o de otras escábridas menores de $0,7 \mathrm{~mm}$. . .4

- Aquenios centrales del capítulo con pico hasta de $1 \mathrm{~mm}$, o sin pico, y con vilano formado por (9)10-20 escamas plumosas, a veces acompañadas de otras escábridas mayores de $(0,5) 1 \mathrm{~mm}$...5

4. Planta anual o bienal, sin restos de hojas de floraciones anteriores; hojas de enteras a pinnatisectas, agudas u obtusas, herbáceas o débilmente coriáceas, laxa- o densamente pilosas, con pelos simples mezclados con otros 2-3-fidos; vilano con las escamas plumosas de 0,18-0,3 mm de anchura en la base 1.T. hispida

- Planta perenne, leñosa en la base, con numerosos restos de hojas de floraciones anteriores; hojas dentadas o lobadas, obtusas, coriáceas, por lo general densamente pelosas, con todos los pelos 2-3-fidos, rara vez mezclados con algunos simples; vilano con las escamas plumosas de $0,10-0,15 \mathrm{~mm}$ de anchura en la base.

2. T. tingitana

5. Planta perenne, leñosa en la base, con numerosos restos de hojas de floraciones anteriores; hojas de 1,2-3 cm de anchura, coriáceas, densamente tapizadas de pelos que casi ocultan la epidermis en el envés; ramas estilares 1,2-1,3 mm; vilano de los aquenios centrales del capítulo de (8)8,5-9 $\mathrm{mm}$, con 10-11 escamas plumosas, acompañadas de una fila externa de escamas escábridas de 1-4 $\mathrm{mm}$. 3. T. Iusitanica

- Planta anual o perenne, no o poco leñosa en la base, por lo general sin restos de hojas de floraciones anteriores; hojas de 0,3-1(2) cm de anchura, coriáceas o herbáceas, glabras o pelosas, a veces densamente, tapizadas de pelos que rara vez ocultan la epidermis en el envés; ramas estilares $0,3-0,8(1) \mathrm{mm}$; vilano de los aquenios centrales del capítulo de 4-8 mm, con (9)10-20 escamas plumosas, acompañadas o no de una fila externa de escamas escábridas de $(0,5) 1-3(4) \mathrm{mm}$

6. Vilano de los aquenios internos del capítulo con (14)16-20 escamas plumosas, a veces con algunas escamas externas y escábridas más pequeñas; hierba perenne, con rizoma horizontal o vertical, leñoso, que emite varias rosetas de hojas cada ciclo reproductor; hojas coriáceas, glabras, pero más frecuentemente pelosas, con pelos (2)3-4-fidos 4. T. glabrata

- Vilano de los aquenios internos del capítulo con (9)10(12) escamas plumosas, acompañadas de otras tantas escamas externas y escábridas más pequeñas; hierba anual con raíz axonomorfa cubierta de raíces en toda su longitud, o con rizoma vertical y premorso, con raíces fasciculadas, generalmente con una sola roseta de hojas en toda la vida de la planta; hojas \pm herbáceas, glabras o menos frecuentemente pelosas, con pelos (1)2(3)-fidos. 5. T. saxatilis

1. Thrincia hispida Roth, Catal. Bot. 1: 99, 100 (1797)

$\equiv$ Apargia incrassata Moench, Suppl. Meth.: 220 (1802), nom. illeg. [nom. superfl.]

$\equiv$ Thrincia nudicaulis subsp. hispida (Roth)

P. Fourn., Quatre Fl. France: 1033 (1940)

$\equiv$ Thrincia saxatilis subsp. hispida (Roth) Holub \& Moravec in Preslia 24: 81 (1952) $\equiv$ Leontodon saxatilis subsp. hispidus (Roth) Castroviejo \& M. Laínz in Laínz, Contr. Fl. Asturias: 71 (1982)

$\equiv$ Leontodon taraxacoides subsp. hispidus (Roth) Kerguélen in Lejeunia, ser. 2, 120: 119 (1987)

Ind. loc.: "Habitat in Hispania"

Lectotipo (designado aquí): GOET-001791.

$=$ Leontodon major Mérat in Ann. Sci. Nat. (Paris) 22: 106 (1831)

= Thrincia hispida var. major Boiss., Voy. Bot. Espagne 2: 378 (1841)

$=$ Thrincia hispida var. minor Boiss., Voy. Bot. Espagne 2: 378 (1841)

$=$ Leontodon rothii Ball in J. Linn. Soc., Bot. 16: 543 (1878), nom. illeg. [nom. superfl.] $\equiv$ Leontodon saxatilis subsp. rothii Maire in Jahandiez \& Maire, Cat. Pl. Maroc. 3: 833 (1934)

ELeontodon taraxacoides subsp. longirostris Finch \& P.D. Sell in Bot. J. Linn. Soc. 71: 247 (1976)

$\equiv$ Leontodon longirostris (Finch \& P.D. Sell) Talavera in Valdés \& al., Herb. Univ. Hispalensis Fl. Select. Cent. 1: 37 (1982)

$\equiv$ Leontodon saxatilis subsp. longirostris (Finch \& P.D. Sell) P. Silva in Bol. Soc. Brot., ser. 2, 60: 155 (1987)

= Thrincia glochidiata Sennen in Sennen, Pl. Espagne 1930 [in schaed.]: No. 7631 (1930) 


\section{Ecología, fenología y distribución}

Pastizales en todo tipo de substratos, en pinares, encinares, alcornocales, etc., y en sus matorrales de sustitución, incluso en cultivos, tanto de herbáceas como de leñosas; 0-1500(2000) m. III-VIII(XII). W de la Región Mediterránea (Península Ibérica, Francia, Córcega, Baleares, Marruecos, Argelia y Túnez), y Macaronesia (Madeira y Canarias); naturalizada en Norteamérica (California) y Albania. Casi toda la Península Ibérica, más rara en la cornisa cantábrica. Esp.: A Ab Al $\mathrm{Av} \mathrm{B} \mathrm{Ba}(\mathrm{Bi}) \mathrm{Bu} \mathrm{C} \mathrm{Ca} \mathrm{Cc} \mathrm{Co} C \mathrm{C}$ Cs $\mathrm{Cu} \mathrm{Ge}$ Gr Gu H Hu J L Le Lo Lu M Ma Mu Na (O) Or P PM[(Mn) Ib Formentera] (Po) S Sa Se Sg So (SS) T Te V Va Vi Z Za. Port.: AAl Ag BA BAL BB BL DL E Mi R TM.

\section{Observaciones}

Especie muy variable en el porte, indumento, número de brácteas internas del involucro y en los aquenios externos del capítulo. Son excepcionalmente raras las plantas totalmente glabras, ya que por lo común las plantas suelen tener las hojas \pm pelosas, pudiendo o no tener los tallos y el dorso de las brácteas del involucro glabros. Las plantas que tienen los tallos glabros suelen tener también las brácteas del involucro glabras, pero no se ha encontrado relación geográfica alguna con respecto a estos caracteres, ya que incluso en las mismas poblaciones puede haber plantas con brácteas glabras y pelosas.

Igual que con el indumento ocurre con el número de brácteas internas del involucro, que puede variar . entre (6) 8 y 13, pero suelen dominar los capítulos con 8 o 12 brácteas. Por lo general, las plantas que tienen menos brácteas internas son más pequeñas en todos sus órganos, tienen menos flores, y suelen presentar una sola fila de aquenios externos en el capítulo. Por el contrario, las plantas que tienen mayor número de brácteas internas suelen ser mayores, con un número de flores más elevado y a menudo presentan hasta 3 filas de aquenios externos en el capítulo. Plantas con 8 brácteas internas son más frecuentes en el norte que en el centro de la Península Ibérica. Las plantas galbras con 12 brácteas internas del involucro fueron descritas de Llivia (Gerona) como Thrincia serotina Sennen in Sennen, P1. Espagne 1925: No 5349 (1925), in sched, [Lectotipo (designado aquí): BC879565). Isotipos: MA138093 \& MA425932)], y las glabras del sureste de España (de "Orcelin", Orihuela, provincia de Alicante) como Thrincia nudicalyx Lag., Gen Sp. Pl: 24 (1816), cuyo tipo no se ha encontrado. No obstante convien señalar que Reichenbach (1830) describió su Thrincia psilocalyx Lag. ex Rchb., Iconogr. Bot. Crit. 8: 20 (1830) a partir de plantas que supuestamente le envió Lagasca, especie que iconografía en la tábula 749, fig. 995, y que coincide en la glabrescencia y en el número de brácteas internas del involucro con la descrita por Lagasca como Thrincia nudicalyx. Es posible que la planta dibujada en la obra de H.G. Reichenbach sea un detalle del tipo que le envió Lagasca, lo que explica que no se encuentre en el herbario del Real Jardín Botánico de Madrid, donde se comnservan la mayoría de los tipos lagascanos. Posiblemente, este mismo origen tienen las plantas descritas como Thrincia pilosiuscula Lag. ex Colla in Herb. Pedem. 3: 554 (1834), y las descritas por Mérat como Leontodon nudicaulis Lag. ex Mérat in Ann. Sci. Nat. (París) 22: 106 (1831) y como Leontodon psilocalyx Lag. ex Mérat in Ann. Sci. Nat. (París) 22: 106 (1831), nom. illeg, non Rchb. (1830). Las plantas de Thrincia seriolensis Pau, Not. Bot. Fl. Españ. 3: 32 (1889), nom. nudum, de Segorbe (Castellón; MA-138238), corresponden a la forma de involucro con 8 brácteas internas y pelosas. A pesar de todas estas variaciones que afectan a la pilosidad y al número de brácteas internas del involucro, los caracteres de las flores, aquenios y vilanos son muy constantes.

De lagunas higroturbosas del Algarve portugués se conocen unas plantas (SEV284450) con hojas estrechas, unas con raíz axonomorfa, 
involucro con 12 brácteas internas, pelosas en el dorso y aquenios internos de 6,5-7 $\mathrm{mm}$, con pico de 2-3,5 mm, como es típico de Thrincia hispida, que conviven con otras más pequeñas, con el rizoma premorso y raíz fasciculada, con los tallos y brácteas del involucro glabros, y aquenios de 3,5-4 mm, con pico de 1-1,2 mm. Estos últimos individuos son más típicos de $T$. saxatilis que de T. hispida, pero las escamas escábridas del vilano, en los aquenios centrales del capítulo, son del tamaño de los de T. hispida. Estos individuos pueden ser el resultado de una hibridación interespecífica entre T. hispida y T. saxatilis.

2. Thrincia tingitana Boiss. \& Reuter, Pugill. P1. Afr. Bor. Hispan.: 68 (1852)

$\equiv$ Leontodon tingitanus (Boiss. \& Reuter) Ball in J. Linn. Soc., Bot. 16: 544 (1878)

Ind. loc.: "Hab. in arenis maritimis prope Tingidem. (Boiss. et Reut.)".

Tipo: no estudiado.

$=$ Leontodon nudicaulis var. perennis Emb. \& Maire in Mém. Soc. Sci. Nat. Maroc 17: 57 (1927)

$\equiv$ Leontodon saxatilis subsp. perennis (Emb. \& Maire) Maire in Jahandiez \& Maire, Cat. Pl. Maroc: 833 (1934)

\section{Ecología, fenología y distribución}

Acantilados y arenales marítimos, sotobosque de quejigares, encinares y pinsapares, en substratos calizos y margosos, o incluso en peridotitas; 0-1350 m. I-XII. Península Ibérica y NW de Marruecos (desde la Península Tingitana hasta el Rif Occidental). Sur de España (Sierras de Algeciras, Subbéticas de Sevilla y Cádiz, y Serranía de Ronda) y CW de Portugal (Estremadura). Esp.: Ca Ma Se. Port.: E.

\section{Observaciones}

Especie muy notoria de la región Tingitana, donde tiene su óptimo, sobre todo en los acantilados marítimos y cuya relación con Thrincia hispida es más que evidente, al menos fenéticamente.

3. Thrincia lusitanica M. Talavera \& S. Talavera, sp. nov.

Holotype: PORTUGAL. Estremadura. Colares, Almoçagene, praia da Andraga, 50 m. 38 $48^{\circ} 08^{\prime \prime} \mathrm{N} / 9^{\circ} 29^{\prime} 05^{\prime \prime} \mathrm{W}$, matorral de Juniperus turbinata, sobre caliza, 5.VII.2012, leg. C. Aedo \& al. CA19119 (MA 864254; VAL211949, isotypus).

Perennial plants, woody at the base with many remnants of leaves from previous flowerings; leaves $1.2-3 \mathrm{~cm}$ wide, coriaceous, densely carpeted with hairs that almost obscure the epidermis on the lower surface coriaceous, lower surface densely carpeted with hairs that almost obscure the epidermis; stylar branches 1.2-1.3 mm; pappus of the internal achenes of the capitulum (8) 8.5-9 mm, with 10-11 plumose hairs accompanied by an external row of scabrid hairs of 1-4 mm.

Hierba perenne, rizomatosa, caulescente, rosulada, pluricaule, muy pelosa, con todos los pelos 2-4-fidos en las hojas y tallos, provistos de un pie de 0,5-2 mm, con los brazos de 0,1-0,2 mm, mezclados con pelos simples en el dorso de las brácteas, enteramente verdosa; rizoma vertical, de 7-10 mm de diámetro en el ápice, leñoso, con numerosos restos de hojas de floraciones anteriores. Tallos 15-20 cm x 1-1,5 $\mathrm{mm}$ de grosor en la base y algo más gruesos en el ápice, de 2-3,5 $\mathrm{mm}$ de diámetro bajo el capítulo, acostillados longitudinalmente, sin hojas bracteiformes, densamente pelosos en toda su longitud, con pelos 2-3-fidos, provistos de un pie de 0,5-2 mm, con los brazos de c. 0,2 $\mathrm{mm}$. Hojas 7,5-15 x 1,2-3 cm, oblanceoladas o subespatuladas, obtusas, atenuadas en un pecíolo corto y ancho, dentadas o débilmente 
lobadas, sobre todo en la mitad inferior, coriáceas, densamente pelosas por ambas caras, con pelos (2)3-4-fidos provistos de un pie de 0,4-1 mm, con los brazos de 0,1-0,2 mm, mucho más densos por el envés, que casi ocultan la epidermis. Capítulos solitarios, péndulos antes de la antesis, erectos en la madurez. Involucro 11-13 x 10-13 mm, cilíndrico-campanulado, con 2 series de brácteas internas y 2-3 series externas o suplementarias, las externas cerca de un tercio de la longitud de las internas; brácteas planas, verdosas, ciliadas en el ápice, con el dorso densamente peloso, con pelos de 0,5-1,5 mm, simples, bífidos, rara vez trífidos, las externas 2-3,5 x 0,8-1 mm, lanceoladas, completamente herbáceas, las internas 9-12 $\mathrm{x}$ 1,5-2 $\mathrm{mm}$, con el margen escarioso en la mitad inferior. Receptáculo alveolado, con los alvéolos de margen poco desarrollado y entero, glabro. Corola de las flores más externas del capítulo de 13-15,5 mm, amarilla, con una banda verdosa en el dorso del limbo, en las flores del centro del capítulo con los dientes de las lígulas amarillos; tubo 3-3,5 $\mathrm{mm}$, viloso en la mitad superior; limbo 10-12 $\mathrm{mm}$, densamente viloso en la mitad inferior del dorso, con los pelos de 1-1,5 mm. Anteras 3,5-4 mm, amarillas. Ramas estilares 1,2-1,3 $\mathrm{mm}$, amarillas. Aquenios dimorfos, los más externos con 5 costillas longitudinales, los demás hasta con 10(12) costillas, glabros, con vilano; los externos del capítulo de 4-5 x 1-1,3 $\mathrm{mm}, \pm$ cónico-truncados, pardos, dispuestos en 2-3 filas, los de la externa con 5 costillas y sin pico, los de la media e interna con hasta 12 costillas y con pico grueso de $0,4-0,6 \mathrm{~mm}$; los centrales del capítulo de 5-5,2 x 0,6-0,7 mm, fusiformes, con pico hasta de $1 \mathrm{~mm}$, provistos de escuámulas erosas transversales por toda su superficie, sin espículos, rojizos. Vilano blancoamarillento, persistente; el de los aquenios externos del capítulo de $0,8-1 \mathrm{~mm}, \pm$ cilíndrico, formado por escamas soldadas entre sí en casi toda su longitud, quedando a modo de corona dentada y glabra; el de los aquenios medios de 7-7,5 mm, la mitad del vilano formado por escamas cortas soldadas entre sí y la otra mitad por escamas lanceoladas escábridas y plumosas, las escábridas de menor longitud que las plumosas, todas planas en la base; el de los aquenios centrales del capítulo de $8-9 \mathrm{~mm}$, formado por 2 filas de escamas aplanadas en la base, la externa de escamas escábridas de 1-4 $\mathrm{mm}$, por lo general 7-8, y la interna con 10(11) escamas plumosas de 0,15-0,20 mm de anchura en la base, más anchos que las externas. $2 n=8$.

\section{Ecología, fenología y distribución}

Acantilados litorales y sabinares, en substrato calcáreo; 20-50 m. VI-X. Endemismo del CW de Portugal. Port.: E.

\section{Observaciones}

Esta especie, endémica del Parque Natural de Sintra-Cascais, es afín a Thrincia saxatilis en la estructura del vilano, y a $T$. glabrata en el porte.

4. Thrincia glabrata Hoffmanns. \& Link, Fl. Portug. 2: 159 (1825-1828)

Ind. loc.: "Dans le Portugal septentrional, aux environs d'O-Porto et ailleurs.".

Neotipo (designado aquí): PORTUGAL. Douro Litoral. Oporto, playa de Valadares, 14 m, 41 $5^{\prime}$ '49'N- 8' 39'27' W, 18-V-2014, Leg. D. Campos, F. J. Jiménez, M. Talavera \& S. Talavera (SEV-284942).

= Thrincia hirta var. crassifolia Welw. ex Mariz in Bol. Soc. Brot. 11: 149, 152 (1893) $\equiv$ Leontodon hirtus raç. crassifolia (Welw. ex Mariz) Samp., List. Esp. Herb. Portug.: 141 (1913)

$\equiv$ Leontodon hirtus var. crassifolius (Welw. ex Mariz) Cout., Fl. Portugal: 667 (1913)

$\equiv$ Leontodon nudicaulis raç. crassifolia (Welw. ex Mariz) Samp., Fl. Portug.: 612 (1947)

$\equiv$ Leontodon saxatilis subsp. crassifolius (Welw. ex Mariz) P. Silva in Bol. Soc. Brot., 
ser. 2, 60: 155 (1987)

\section{Ecología, fenología y distribución}

Pastizales de dunas fijas, rara vez en acantilados marítimos; 0-50 m. (I)IV-X. SW de Francia (desde Bayona hasta Nantes), y Península Ibérica. NW de Portugal, desde Estremadura hasta Miño, y NW de España, desde Pontevedra hasta Guipúzcoa. Esp.: Bi C Lu O Po S SS. Port.: BL DL E Mi.

\section{Observaciones}

En el SW de Francia y en el País Vasco las plantas son más gráciles y con mayor frecuencia mas glabras que las del resto del área de distribución. Estas plantas fueron descritas como Leontodon hastile var. arenarium Duby, Bot. Gall. 1: 308 (1828) [三 Thrincia hirta var. arenaria (Duby) DC., Prodr. 7: 99 (1838); $\equiv$ Thrincia arenaria (Duby) Martrin-Donos, Fl. Tarn: 396 (1864); 三 Leontodon hirtus var. arenarius (Duby) Cout., F1. Portugal: 667 (1913). Ind. loc: “In sabuletis maritimis agri Syrtici propé Teste de Buch reperiit cl. Dufour.”. Lectotipo (designado aquí): “ 51 / Leontodon hastile? Excl.. syn. / non est Picris danubialis all. Tab. 70 / M. Dufour 1821/ les dunes du [i?] d Arcachon [m. Dufour]", etiqueta única (G-DC: 00473461)]. El material tipo está formado por una planta completa con hojas lineares, glabras y dos escapos con capítulos, uno en flor y el otro en fruto.

Las plantas de Portugal y Galicia son por lo general más robustas, y en su mayoría pelosas, y fueron denominadas, sobre todo las de Estremadura, como Thrincia hirta var. crassifolia Welw. ex Mariz [Lectotipo (designado aquí): J. Daveau, Herbarium Lusitanicum $\mathrm{n}^{\circ}$ 63. Ilhas Berlena e Farilhoës - Maio 1883 (LISU); de las tres plantas que componen el pliego se elige como lectotipo la planta en flor del centro del pliego, las otras dos plantas son isolectotipos]. Por el contrario, las de las dunas cercanas a Oporto, son glabras o subglabras, y fueron descritas como Thrincia glabrata Hoffmanns. \& Link. Aunque el tipo de Hoffmannsegg y Link posiblemente se destruyó durante la $2^{\text {a }}$ Guerra Mundial, todas las plantas estudiadas de los alrededores de Oporto coinciden con la descripción realizada por estos autores, por lo que no se tienen dudas de la identidad de la planta.

De las proximidades a Lagoa de St. Andre, en el distrito de Setúbal (Estremadura), proceden plantas conservadas en el herbario de LISU muy parecidas a las perennes de Thrincia saxatilis, pero con los vilanos formados por más de 14 pelos plumosos, como es característico de Thrincia glabrata. Es posible que estos individuos sean el resultado de una hibridación entre estas dos especies.

En Beira Alta, A.R. da Cunha recolectó esta especie (1886) cerca de la playa del pantano de Moledo(LISU). Probablemente, la presencia en Beira Alta puede ser debida a una colonización reciente en esa época.

5. Thrincia saxatilis (Lam.) Holub \& Moravec in Preslia 24: 74 (1952)

$\equiv$ Leontodon saxatilis Lam., Fl. Franç. 2: 115 (1779) [basión.]

Ind. loc.: "Cette plante croît sur le bord des chemins \& dans les lieux secs \& pierreux" [Francia].

Lectotipo (designado aquí): "Leontodon saxatile N. [m. Lamarck]” (P-LAM:0055947). El material tipo está formado por dos plantas completas; se elige la mayor como lectotipo.

= Hyoseris taraxacoides Vill., Prosp. Hist. P1. Dauphiné: 33 (1779) [Apr.]

$\equiv$ Colobium hispidum Roth in Arch. Bot. (Leipzig) 1: 38 (1796), nom. superfl.

$\equiv$ Leontodon taraxacoides (Vill.) Mérat in Ann. Sci. Nat. (Paris) 22: 108 (1831), nom. illeg., non Hoppe \& Hornsch., Tageb. Reise Adriat.: 166 (1818)

$\equiv$ Leontodon nudicaulis subsp. taraxacoides (Vill.) Schinz \& Thell. in Bull. Herb. 
Boissier, ser. 2, 7: 389 (1907)

$\equiv$ Thrincia nudicaulis subsp. taraxacoides

(Vill.) P. Fourn., Quatre Fl. France: 1033 (1940)

$\equiv$ Leontodon saxatile subsp. taraxacoides

(Vill.) Emb. \& Maire in Jahandiez \& Maire, Cat. Pl. Maroc: 1165 (1941)

$\equiv$ Thrincia saxatilis subsp. taraxacoides

(Vill.) Holub \& Moravec in Preslia 24: 75 (1952)

$\equiv$ Colobium taraxacoides (Vill.) Holub in

Folia Geobot. Phytotax. 12: 307 (1977)

= Thrincia hirta Roth, Catal. Bot. 1: 98 (1797)

= Thrincia leysseri Wallr., Sched. Crit.: 441 (1822)

$\equiv$ Leontodon leysseri (Wallr.) Beck, Fl.

Nieder-Österreich: 1312 (1893)

- Leontodon nudicaulis sensu Sampaio, Fl. Portug.: 612 (1937), pr. parte

- Leontodon hirtus sensu Coutinho, Fl. Portugal: 667 (1913), pr. parte

\section{Ecología, fenología y distribución}

Prados alpinos, turberas y lagunas higroturbosas, rara vez en acantilados o arenales marítimos; 0-1495 m. (I)III-XI. Eurasia y Macaronesia (Azores); naturalizada en América. Mitad norte de la Península Ibérica y litoral atlántico, desde Galicia hasta Cádiz. Esp.: Av B Bu Ca Cc Cs Cu Ge Gu H Hu L Le Lo Lu M Na O Or Po S Sa Se Sg So SS T Te To V Va Vi Z Za. Port.: AAL (Ag) BA BAl BB BL DL E Mi R TM.

\section{Observaciones}

Las plantas del interior de la Península Ibérica, sobre todo las que habitan en los prados alpinos o montanos, suelen ser pequeñas, de 4-15 cm, con los tallos capilares, de 0,5-0,6 $\mathrm{mm}$ de diámetro en la base, con las hojas por lo general pinnatífidas, algo coriáceas, casi siempre glabras, e involucro con 8(12) brácteas internas. Estas plantas, que son casi siempre perennes (rara vez bienales), que tienen rizoma premorso, muy corto y con las raíces fasciculadas, se identifican con Leontodon saxatilis Lam., descrita de Francia. El otro extremo de variación los constituyen las plantas que viven en las lagunas higroturbosas del litoral atlántico del SW de la Península Ibérica, y que son extraordinariamente frecuentes en los sistemas lagunares del Parque Nacional de Doñana, y más raras en las lagunas del litoral de Cádiz y de Portugal. Estas plantas suelen ser algo mayores, hasta de $25 \mathrm{~cm}$, anuales y con raíz axonomorfa, muy rara vez perennes y con las raíces fasciculadas, tienen los tallos algo más robustos -hasta de $1 \mathrm{~mm}$ de diámetro en la base- y las hojas herbáceas, por lo general pelosas, lineares, dentadas, y el involucro con 8(12) brácteas internas, glabras o pelosas en el dorso. Han sido denominadas por los botánicos portugueses como Leontodon hirtus var. arenarius [cf. Coutinho, Fl. Portugal: 667 (1913)], Leontodon nudicaulis raç. arenarius [cf. Sampaio, Fl. Portug.: 612 (1937)], Thrincia hirta var. arenaria [cf. Mariz in Bol. Soc. Brot. 11: 149 (1893)] o Leontodon hirtus var. filicaulis Samp. in Bol. Soc. Brot. 24: 63 (1909), y por los españoles como Leontodon taraxacoides [cf. Valdés, Talavera y Galiano, Fl. Andalucía Occid. 3: 100 (1987)]. Esta segunda pauta de variación ha sido observada también en lagunas y turberas de tierras altas de la mitad norte de la Península Ibérica [Esp.: Av B Bu $\mathrm{C} \mathrm{Cc} \mathrm{Cu} \mathrm{Lu} \mathrm{M} \mathrm{O} \mathrm{Or} \mathrm{Po} \mathrm{S} \mathrm{Sa} \mathrm{Sg} \mathrm{So} \mathrm{Te} \mathrm{To} \mathrm{Z}$ Za. Port.: AAl BA BB Mi], muy similares a las anteriores y a las representadas en el icón de Hyoseris taraxacoides de la obra de Villar [Hist. Pl. Dauphiné 3 (1789)], por lo que no se ha creído oportuno asignarles categoría taxonómica alguna.

6. Thrincia tuberosa (L.) DC. in Lam. \& DC., F1. Franç., ed. 3, 4: 52 (1805)

इLeontodon tuberosum L., Sp. Pl.: 799 (1753) [basión.] 
$\equiv$ Picris tuberosa (L.) All., Fl. Pedem. 1: 210 (1785)

$\equiv$ Apargia tuberosa (L.) Willd., Sp. Pl. 3: 1549 (1803)

$\equiv$ Apargia bulbosa Balb. in Mém. Acad. Imp. Sci. Turin, Sci. Phys. 15: 224 (1808), nom. illeg. [nom. superfl.]

$\equiv$ Thrincia nudicaulis subsp. tuberosa (L.)

P. Fourn., Quatre Fl. France: 1033 (1940)

Ind. loc.: "Habitat in Hetruriae, Galloprovinciae, Narbonae pratis".

Lectotipo: designado por Alavi (1983: 353; Her. Linn. No. 953.5; LINN).

= Thrincia grumosa Brot., F1. Lusit. 1: 325 (1804)

$\equiv$ Hyoseris grumosa (Brot.) Poir. in Lamarck, Encycl. Suppl. 3: 82 (1813)

$=$ Hyoseris tuberosa var. oliverii DC., Prodr.

7: 1100 (1838)

$\equiv$ Thrincia oliverii (DC.) Hausskn. in Mitth.

Thüring. Bot. Vereins 7: 58 (1895)

$\equiv$ Leontodon tuberosum subsp. oliverii (DC.) Holmboe in Bergens Mus. Skr., ser. 2, 1: 192 (1914)

$\equiv$ Leontodon oliverii (DC.) Prain, Index Kew., Suppl. 5: 149 (1921)

= Thrincia tripolitana Boiss., Fl. Orient., Suppl.: 319 (1888)

= Apargia cichoriacea Ten., F1. Napol. 1: XLVI (1811-1838)

- Thrincia tuberosa f. gracilis Sennen in Sennen, Pl. Espagne 1926: nº 5787 (1926), nom. nudum

\section{Ecología, fenología y distribución}

Pastizales de enclaves \pm húmedos en pinares, rebollares, praderas, etc., en substratos diversos (calizas, margas, arenas, esquistos, etc.); 3-880 m. XI-V. Región Mediterránea. Casi todo el territorio, aunque más rara en la mitad oriental. Esp.: A Av B Ba Bu C Ca Cc Co CR Ge H J Lo Lu M Ma O Or PM[Mll Me] Po Sa
Se T V Za. Port.: AAl Ag BAl BL DL E R TM.

Observaciones

Especie poco variable, muy bien diferenciada del resto de las especies del género, tanto en lo morfológico como desde el punto de vista citológico, ya que es la única especie del género con todos los cromosomas cefalobranquiales.

Se ha observado en ellas que a veces el rizoma vertical se desarrolla bastante, disponiéndose los tubérculos fasciculados en la base del rizoma. Estas plantas con rizoma \pm largo fueron descritas como Thrincia squamata Caball. in Bol. Soc. Esp. Hist. Nat. 12: 508 (1912) [Ind. loc.: "hábitat in declivis septentrionalis locis argillosis monte Gurugú supra Mezquita. April.”. Lectotipo (designado aquí): "Thrincia squamata Caballero / Melilla / Leg. [impreso] / 5-1912- Caballero [m. Caballero]" (MA-138242)]. El material tipo contiene dos plantas, y se elige como lectotipo la montada a la derecha, con rizoma vertical hojas runcinadas y dos escapos, uno en flor y el otro sin capítulo. Este tipo de rizoma es raro en la Península Ibérica, pero con cierta frecuencia se ha detectado en algunas plantas del sur de España y del Algarve portugués.

7. Thrincia maroccana Pers., Syn. P1. 2: 368 (1807)

$\equiv$ Hyoseris hispida Schousb. in Kongel. Danske Vidensk.-Selsk. Skr. 1: 197 (1800), sin. subst.

$\equiv$ Thrincia mauritanica Spreng., Syst. Veg. 3: 666 (1826), nom. illeg. [nom. superfl.] $\equiv$ Leontodon maroccanus (Pers.) Ball in J. Linn. Soc. Bot. 16: 544 (1878)

Ind. loc.: "In montosis aridis prope Mequenesiam. In H. bot. Hafn.”.

Lectotipo (designado aquí): "Hyoseris hispida Schousb.” (C-10007627). El tipo lo constituye una sola planta en floración, y de acuerdo con la información que aparece en el 
dorso del pliego, procede de los cultivos en el "HH" [Hortus Botanicus Hafniense], como indicó Schousboe cuando describió la especie.

\section{Ecología , fenología y distribución}

Pastizales de marismas, lagunas y terrenos temporalmente encharcados durante el invierno, en substratos arcillosos, a veces \pm salinos, rara vez en areniscas e incluso en cultivos; 0-480 m. II-V(VII). W de la Región Mediterránea: Península Ibérica, Marruecos y, posiblemente, también en Argelia. CW de Portugal (Ribatejo) y Sur de España. Esp.: Ca Co H Ma Se. Port.: R.

\section{Observaciones}

En la Reserva Natural do Estuário do Tejo (Ribatejo, Portugal) se han detectado individuos que, como Thrincia maroccana, tienen pelos subestrellados en el margen y dorso de las brácteas internas del involucro, con aquenios externos pubescentes y el vilano de los aquenios internos formado por 15-16 setas plumosas. Estas plantas portuguesas se diferencian de las que aparecen en el resto de poblaciones, tanto de España como de Marruecos, porque el dorso del limbo de las flores más externas del capítulo es glabro, el vilano de los aquenios externos del capítulo es de c. $1 \mathrm{~mm}$, campanulado, glabro, blanco, y está formado por escamas soldadas entre sí solo en la mitad inferior. Sobre la base de estas características y el aislamiento geográfico de las plantas del Ribatejo, se han descrito están plantas como una nueva subespecie.

\section{Clave para las subespecies}

1. Corola de las flores más externas del capítulo con el dorso del limbo densamente viloso casi hasta el ápice; vilano de los aquenios externos del capítulo de $(1,1) 1,5-2,2 \mathrm{~mm}$, cilíndrico, pubescente, pardusco o blancoamarillento, formado por escamas soldadas entre sí en casi toda su longitud.

a. subsp. maroccana

- Corola de las flores más externas del capítulo con el dorso del limbo glabro, con pelos solo en el margen; vilano de los aquenios externos del capítulo de c. $1 \mathrm{~mm}$, campanulado, glabro, blanco, formado por escamas soldadas entre sí solo en la mitad inferior ..b. subsp. ribatejana

a. subsp. maroccana

Tallos de 1,5-1,8(2,5) mm de diámetro en la base, más gruesos en el ápice -hasta de 3 mm de diámetro bajo el capítulo-, sin hojas bracteiformes, glabros o pelosos, sobre todo en la base, \pm rojizos en la mitad inferior. Involucro (8)10-15(18) x (5)9-11 mm, cilíndrico o campanulado, con 1-2 series de brácteas internas y 1-3 suplementarias o externas, las externas de un tercio a cerca de un medio la longitud de las internas; brácteas externas de 3-6(7) x 0,4-1,5(2) mm, las internas -en número de 8 ó 13- de 8-12(15) x 2-3,3 mm. Corola de las flores más externas del capítulo de 9-16 mm; tubo $(2) 3-5(5,5) \mathrm{mm}$; limbo 7-12 $\mathrm{mm}$, con el dorso casi enteramente viloso. Vilano pardusco o blanco-amarillento; el de los aquenios más externos del capítulo de $(1,1) 1,5-2,2 \mathrm{~mm}, \pm$ cilíndrico, pubescente, formado por escamas soldadas entre sí en casi toda su longitud, quedando a modo de corona dentada; el de los aquenios internos del capítulo de $(5,5) 6-8 \mathrm{~mm}$, blanco-amarillento. $2 n=8$.

\section{Ecología, fenología y distribución}

Pastizales de marismas, lagunas y terrenos temporalmente encharcados durante el invierno, cultivos, etc., en substratos arcillosos, a veces salinos, rara vez en areniscas; 0-480 m. II-V(VI). W de la Región Mediterránea: España, Marruecos y posiblemente también en Argelia. Sur de España, en las sierras de Algeciras y en los valles de los ríos Guadalquivir, Guadalete y Guadalhorce. Esp.: Ca Co H Ma Se.

b. subsp. ribatejana Talavera \& M. Talavera subsp. nov.

Holotype: Portugal. Ribatejo, Pancas, tanque do sapal. Duna con vegetaçao herbácea e 
cum Quercus suber, 15-julhio-1982, M. Correia \& J. Cardoso lecta (LISU).

Plant annual; external flowers of the capitulum with the dorsal limb glabrous and hairs restricted to the margin, in contrast to the densely villous limb, almost to the apex, in T. maroccana subsp. maroccana; pappus of the external achenes of the capitulum around $1 \mathrm{~mm}$, campanulate, glabrous, white, formed by scales that are fused to each other in the lower half, whereas in T. maroccana subsp. maroccana the pappus is (1.1-) 1.5-2.2 $\mathrm{mm}$, cylindrical, pubescent, brownish or whitish-yellow, formed by scales that are fused to each other for almost their whole length.

Tallos de 0,9-1,1 mm de diámetro en la base, cilíndricos o subcilíndricos, algo más gruesos en el ápice -hasta de 1,5 mm de diámetro bajo el capítulo-, con 1 hoja bracteiforme en el tercio superior, glabros, enteramente verdosos. Involucro 8,5-9 x 6-7 mm, campanulado, con 1 serie de brácteas internas y 2 de externas, las externas de un quinto a un cuarto la longitud de las internas; brácteas externas 1,5-2,5 x 0,2-0,5 $\mathrm{mm}$, las internas -en número de 8 - de 7,8-8,1 x 1,5-2 mm. Corola 9-10,5 mm; tubo 2,5-3,5 mm; limbo 6,5-7 mm, con el dorso glabro. Vilano blanco; el de los aquenios más externos del capítulo de c. $1 \mathrm{~mm}, \pm$ campanulado, glabro, formado por escamas soldadas entre sí solo en la mitad inferior, quedando a modo de corona festoneada; el de los aquenios internos de 4,5-5 $\mathrm{mm}$, blanco.

\section{Ecología, fenología y distribución}

Pastizales en el estuario del río Tajo; c. 10 m. VII. Endemismo de CW de Portugal (Ribatejo). Port.: R.

Leontodon L., Sp. Pl: 799 (1753)

Hierbas perennes, rizomatosas, a veces estoloníferas, caulescentes, escaposas, excepcionalmente foliosas, inermes, estrigosas, vilosas o glabrescentes, con indumento formado por pelos eglandulosos 2-10-fidos, pediculados, o subsésiles y \pm estrellados, con frecuencia mezclados con otros simples, indivisos, en proporciones variables, sobre todo en las hojas, tallos y en el dorso de las brácteas del involucro; rizoma subterráneo, vertical u oblicuo, corto y grueso, u horizontal, largo y delgado, los verticales y oblicuos por lo general ramificados en el ápice, leñosos, que originan rosetas de hojas cada ciclo reproductor. Tallos erectos, acostillados, cilíndricos, a veces de mayor diámetro en el ápice, ápteros, simples, monocéfalos, excepcionalmente ramificados en la base, con ramas monocéfalas, afilos o con 1-2 bráctes en el tercio superior, muy rara vez con 1 hoja \pm desarrollada, a veces bajo la bifurcación del tallo, glabros o pubescentes. Hojas uninervadas, pinnatinervias, elípticas o más frecuentemente oblanceoladas, atenuadas en la base en un pecíolo ancho y alado, o estrecho y áptero, enteras, dentadas o más frecuentemente pinnatífidas o pinnatisectas, runcinadas, de consistencia herbácea, a veces \pm coriáceas, glabras o glabrescentes, pero por lo general \pm estrigosas, con pelos \pm pediculados 2-7-fidos, a veces junto a pelos simples, \pm verdosas o cenicientas. Capítulos péndulos o erectos antes de la antesis, solitarios, en el extremo de los tallos, multifloros. Involucro con 2-5 series de brácteas \pm erectas, adpresas, las externas mucho más cortas que las internas; brácteas planas, ovadas, elípticas, lanceoladas, linear-lanceoladas o linear-elípticas, por lo general obtusas, herbáceas o las más internas con el margen escarioso en la mitad inferior, frecuentemente con el dorso cubierto de pelos 2-10-fidos, pero a veces mezclados con pelos aculeiformes simples, sobre todo en el nervio medio, rara vez glabrescentes, ventralmente glabras. Receptáculo alveolado, con los alvéolos de margen escarioso, \pm ancho y dentado, a veces los más internos del capítulo con algunos pelos o cilios cortos, mucho más 
cortos que los ovarios. Flores liguladas, con 5 dientes, hermafroditas, las externas del capítulo mayores que las internas. Corola con el tubo glabro o \pm peloso en el ápice y el limbo viloso solo en la base, amarilla o con los dientes de la lígula \pm purpúreos, a menudo las mas externas del capítulo con una banda verdosa, rosada o purpúrea en el dorso del limbo. Anteras amarillas. Ramas estilares amarillas. Aquenios homomorfos, cilíndricos o fusiformes, a veces los más externos del capítulo \pm incurvos, sin pico o con pico más corto que el cuerpo, con 5-12(15) costillas longitudinales provistas de escuámulas transversales \pm marcadas, a veces con espículos blancos, sobre todo en la mitad superior, glabros, pardos o pardo-rojizos, con vilano. Vilano plumoso, casi de la longitud del aquenio, amarillento o blanco, persistente, formado por 2-3 filas de pelos y escamas setiformes, aplanadas en el tercio inferior, las más externa de pelos escábridos, la media -cuando existe- y la interna de escamas setiformes y plumosas, con la fila más interna -la de mayor tamaño- formada por 8-14(15) escamas. $x=4,6,7$.

Especie tipo: Leontodon hispidus L. Sp. Pl.: 799 (1753), designado por Green (1929: 178).

\section{Observaciones}

Género complejo y probablemente parafilético, con cerca de 20 especies (excluidas las de Thrincia), en su mayoría endémicas de la Región Mediterránea. Recientemente, Enke \& al. (2012) han llevado las especies de Hedypnois al género Leontodon, pero en Flora iberica el género Hedypnois se trata independientemente.

\section{Clave para las especies}

1. Tallos y brácteas del involucro cubiertos de pelos subestrellados 5-10-fidos, con pedículo menor de $0,2 \mathrm{~mm}$; aquenios con numerosos espículos en el tercio superior, sin pico...4. L. farinosus

- Tallos y brácteas del involucro cubiertos de pelos pediculados 2-4-fidos, con pedículo generalmente mayor de $0,4 \mathrm{~mm}$, o glabros; aquenios con espículos o sin ellos en el tercio superior, con pico o sin pico

2. Planta de (5)10-60(85) cm de altura; hojas (2)4-30 x 1-4(5) cm; rizoma horizontal u oblicuo, simple o ramificado en toda su longitud, sin restos de hojas de floraciones anteriores; aquenios sin espículos, subcilíndricos, sin pico1.L. hispidus

- Planta de 2-24 cm de altura; hojas 1,3-9 x 0,2-2,2 $\mathrm{cm}$; rizoma vertical, por lo general ramificado en el ápice, con numerosos restos de hojas de floraciones anteriores; aquenios con numerosos espículos en el tercio superior, subcilíndricos o fusiformes, con pico o sin pico ........................ 3

3. Involucro 8-10 x 5-7 mm; aquenios 5,5-7 $\mathrm{mm}$, subcilíndricos, sin pico; vilano 6-7 mm .....................................2. L. caroliaedoi

- Involucro 10-17 x (4)6-11 mm; aquenios 6-10 $\mathrm{mm}$, fusiformes, atenuados en un pico de 1-3 $\mathrm{mm}$; vilano 8-10 $\mathrm{mm}$....................................... 4

4. Planta de (2)3-6(9) cm de altura; aquenios 6-8 $\mathrm{mm}$, con pico de $1-2 \mathrm{~mm}$; corola de las flores más externas del capítulo con el dorso de la lígula purpúreo, en las centrales completamente amarilla . 3. L. boryi

- Planta de 13-24 cm de altura; aquenios 8-10 mm, con pico de 2-3 mm; corola de las flores más externas del capítulo amarilla por ambas caras, salvo los dientes que son purpúreos como en las flores centrales 5. L. crispus

1. Leontodon hispidus L., Sp. Pl.: 799 (1753) $\equiv$ Hedypnois hispida (L.) Huds., Fl. Angl., ed. 2: 342 (1778)

$\equiv$ Leontodon proteiformis Vill., Prosp. Hist. P1. Dauphiné: 34 (1779), nom. superfl.

$\equiv$ Picris hispida (L.) All., Fl. Pedem. 1: 210 (1785)

$\equiv$ Apargia hispida (L.) Hoffm., Deutschl. F1.: 274 (1791)

$\equiv$ Picris acaulis Bernh., Syst. Verz.: 141 (1800), nom. superfl.

三Virea hispida (L.) Gray, Nat. Arr. Brit. Pl. 2: 429 (1821).

$\equiv$ Apargia communis Spenn., Fl. Friburg.: 558 (1826), nom. superfl.

$\equiv$ Leontodon hastilis var. hispidus (L.) Boiss., Fl. Orient. 3: 730 (1875)

Ind. loc.: "Habitat in europae pratis".

Lectotipo: designado por Pittoni (1973: 129; Magnol, LINN No. 953.9). 


\section{Ecología, fenología y distribución}

En sotobosque de pinares, rebollares, abetales, etc., y con mucha frecuencia en praderas montanas o alpinas \pm húmedas, en substrato de granitos, calizas o esquistos; (350)650-2000(2270) m. (V)VI-VIII(IX). Eurasia; adventicia o naturalizada en Norteamérica. C y N de la Península Ibérica. And. Esp.: Av B Bu C Ce $\mathrm{Cu} \mathrm{Ge} \mathrm{Gu} \mathrm{Hu} \mathrm{L} L e$ Lo Lu M Na O Or P S Sa Sg So SS Te Vi Z Za. Port.: BA Mi.

\section{Observaciones}

En la Península Ibérica la especie presenta gran variabilidad en lo concerniente al sistema radical, a la morfología e indumento de las hojas, al color de las flores y a la escultura de los aquenios. Al parecer, Leontodon hispidus puede reproducirse por agamospermia mediante aposporia (Bergman, 1935; Battaglia, 1951), lo que puede explicar la variación en el número cromosómico y también buena parte de la variabilidad morfológica que presenta en Eurasia.

En el norte de España, viviendo sobre todo en prados alpinos, son frecuentes los individuos con raíz premorsa, gruesa y oblicua; tallos por lo general con 1 hoja bracteiforme; hojas de enteras a pinnatífidas, glabras o más a menudo muy pelosas, con pelos 2-3(4)-fidos; lígulas de las flores centrales del capítulo con dientes purpúreos, y aquenios por lo general con 5 costillas, con las escuámulas transversales muy marcadas. Este morfotipo es el más frecuente también en el resto de Europa, y se identifica con el tipo linneano de Leontodon hispidus.

En el Sistema Central, Sistema Ibérico y en las estribaciones más occidentales de la Cordillera Cantábrica, predominan las plantas con rizoma horizontal, alargado, delgado y noduloso, a veces estolonífero, que originan poblaciones apomícticas por multiplicación vegetativa. Además, los tallos casi siempre no presentan hojas bracteiformes; las hojas son enteras o pinnatífidas, pelosas o glabrescentes, y los pelos muy frecuentemente son 3-5-fidos; las lígulas de las flores centrales del capítulo son generalmente plenamente concoloras, amarillas, y los aquenios, a menudo con 10-12(15) costillas estrechas, tienen las escuámulas transversales poco marcadas.

Estas dos pautas de variación se han reconocido aquí con categoría de subespecie, a pesar de que dentro del área de distribución de la segunda aparecen individuos intermedios entre las dos, posiblemente debido a la hibridación entre ellas.

\section{Clave para las subespecies}

1. Rizoma de (2,5)5-10 $\mathrm{mm}$ de diámetro, corto, oblicuo; hojas glabras o pelosas, con los pelos 2-3(4)-fidos; corola de las flores centrales del capítulo con los dientes purpúreos; aquenios por lo general con 5 costillas anchas provistas de escuámulas transversales muy marcadas ............................... subsp. hispidus

- Rizoma de 1,5-4 mm de diámetro, largo, noduloso, horizontal, a veces estolonífero; hojas glabras o pelosas, con los pelos (2)3-4(5)-fidos; corola de las flores centrales del capítulo con los dientes por lo general amarillos; aquenios casi siempre con 10-12(15) costillas estrechas, provistas de escuámulas transversales poco marcadas b. subsp. bourgaeanus

\section{a. subsp. hispidus}

= Leontodon hastilis L., Sp. Pl., ed. 2: 1123 (1763) [Ind. loc.: "Habitat in Europa australi". Lectotipo: no encontrado)]

$\equiv$ Virea hastilis (L.) Gaertn., Fruct. Sem. Pl.

2: 365 (1791)

三Apargia livida Moench, Methodus: 542 (1794), nom. superfl.

三Apargia hastilis (L.) Host., Syn. Pl.: 423 (1797)

$\equiv$ Leontodon hastilis var. glabratus W.D.J. Koch, Syn. Fl. Germ. Helv., ed. 2: 482 (1844)

$\equiv$ Leontodon hispidus var. glabratus (W.D.J. Koch) F.W. Schultz, Fl. Pflanz.: 261 (1845), nom. illeg.

$\equiv$ Leontodon proteiformis subsp. hastilis (L.) 
Arcang., Comp. Fl. Ital.: 417 (1882)

$\equiv$ L. hispidus subsp. hastilis (L.) Corb., Nouv. Fl. Normandie: 370 (1894)

$\equiv$ Virea hispida var. hastilis (L.) House in Bull. New York State Mus. Nat. Hist. 242-244: 69 (1923)

= Leontodon pinetorum Pau in Bol. Soc. Iber. Ci. Nat. 23: 105 (1925)

$=$ Leontodon proteiforme var. crispatus Gren. in Grenier \& Godron, Fl. France 2: 299 (1850)

$\equiv$ L. hispidus f. crispatus (Gren.) Willk., Suppl. Prodr. Fl. Hispan.: 109 (1893)

\section{Ecología, fenología y distribución}

Sotobosque de abetales, pinares, hayedos, robledales, etc., pero más común en praderas y paredones húmedos, montanos o alpinos; (350)650-2000(2270) m. (V)VI-VII. Eurasia; adventicia en diversas regiones de América del Norte. $\mathrm{N}$ y $\mathrm{C}$ de la Península Ibérica. And. Esp.: B Bu C Cc Ge Hu L Le Lo Lu M Na P S Sg So SS Te Vi Z. Port.: BA Mi.

\section{Observaciones}

De los pinares de La Granja [de San Rafael o de San Ildefonso], en Segovia, describió Carlos Pau (1925: 105) su Leontodon pinetorum Pau in Bol. Soc. Iber. Ci. Nat. 23: 105 (1925), a partir de una planta recolectada por Francisco Beltrán y Carlos Vicioso, el 31 de julio de 1912, dato que Pau omitió en la publicación. El material tipo, que se encuentra en el herbario del Real Jardín Botánico de Madrid [Lectotipo (designado aquí): MA137857], consta de una planta completa, de $30 \mathrm{~cm}$ de altura, con rizoma, hojas y un solo tallo monocéfalo en postantesis, más un tallo de $40 \mathrm{~cm}$, monocéfalo y también en postantesis. El rizoma es oblicuo y algo más largo y delgado -unos 2,5 mm de diámetrode lo que es habitual en L. hispidus subsp. hispidus; las hojas, de 15,5-20 x 1,5-2,5 mm, son largamente pecioladas, elípticas, enteras o muy débilmente denticuladas, glabrescentes -como los escapos y las brácteas del involucro-, con algunos pelos 2-3-fidos de 0,3-0,5 mm, dispersos por el limbo, más evidentes en el nervio medio del envés; los aquenios de c. 6 $\mathrm{mm}$, casi desarrollados, y el vilano, de unos 8 $\mathrm{mm}$, tiene 12 escamas plumosas más largas que las demás. Esta planta con rizoma es la que se elige como lectótipo.

Plantas glabras o glabrescentes son relativamente frecuentes en toda el área de distribución de L. hispidus y se corresponden con lo que se ha descrito como Leontodon hastilis L., Sp. Pl., ed. 2: 1123 (1763), que puede tener las hojas enteras, como en $L$. pinetorum, o divididas, que es lo habitual en la especie.

En España, sobre todo en el noreste [Esp.: L Ge] y al oeste del Sistema Central [Esp.: $\mathrm{Cc}$, hay poblaciones con plantas de hojas muy ásperas, lo que deben al denso indumento que poseen, de pelos bífidos y trífidos. Estas plantas, sobre todo las del Pirineo más oriental, fueron reconocidas como L. hispidus f. crispatus (Gren.) Willk.

b. subsp. bourgaeanus (Willk.) Rivas Mart. \& Sáez in Anales Jard. Bot. Madrid 35: 157 (1980)

$\equiv$ Leontodon bourgaeanus Willk. in Willk. \& Lange, Prodr. Fl. Hispan. 2: 217 (1865), basión.

$\equiv$ Leontodon crispus subsp. bourgaeanus (Willk.) Finch \& P.D. Sell in Bot. J. Linn. Soc. 71: 246 (1976)

Ind. loc.: "In pascuis montium Carpetanorum (Sierra de Guadarrama, BOURG.!)". ["L. hispidum COSS. ap BOURG. pl. hisp. exsicc. 1854, n. 2234! non L.".

Lectotipo (designado aquí): COI-Willk.!; isotipo: G00404554!).

\section{Ecología, fenología y distribución}

En sotobosque de melojares, hayedos y alisedas, así como en pedregales y pastizales ralos, por lo general en substratos graníticos, 
rara vez en micaesquistos; (800)8902000(2400). VI-VIII(IX). Endemismo de la Cordillera Central, Sistema Ibérico y extremo más occidental de la Cordillera Cantábrica. Esp.: Av Bu Cc Cu Gu Le Lu M O Or P Sa Sg So Te Vi Z Za. Port.: BA Mi.

\section{Observaciones}

Finch \& Sell (1976) asimilaron esta subespecie a Leontodon crispus, pero los caracteres que presentan las plantas están mucho más relacionados con L. hispidus, criterio seguido aquí. Es muy común en la Sierra de Guadarrama, de donde fue descrita, y en algunas sierras del norte de la Península Ibérica (Rivas Martínez \& Sáez, 1980), y mucho más rara en el resto de su área de distribución.

El estudio de los materiales tipo de $L$. bourgaeanus, que se conservan en Coimbra (COI-Willk.) y en Ginebra (G), indica que la especie presenta plantas con rizoma oblicuo, de 3,5-4 mm de diámetro; tallos de c. 1,5 mm de diámetro en la base, simples, glabrescentes, engrosados en el ápice, hasta c. 2,8 $\mathrm{mm}$ de diámetro bajo el capítulo; hojas lanceoladas, atenuadas en la base en un pecíolo ancho y alado, de pinnatífidas a pinnatipartidas, runcinadas, con los lóbulos lanceolados, distantes, densamente cubiertas de pelos (2)3-4-fidos, con un pie de 0,2-0,8 $\mathrm{mm}$ y con brazos de $0,1-0,2 \mathrm{~mm}$ y patentes; capítulos solitarios; involucro con el dorso cubierto de setas aculeiformes de 3,5-5 mm, la mayoría simples, algunas bífidas y con los dientes desiguales y erecto-patentes; corola c. $18 \mathrm{~mm}$, con los dientes de las lígulas internas del capítulo purpúreos por el dorso; aquenios c. $5 \mathrm{~mm}, \pm$ fusiformes, con c. 12 costillas longitudinales, y vilano c. $10 \mathrm{~mm}$, con la fila más interna formada por 12 escamas largas y plumosas. Aunque algunos de estos caracteres no encajan del todo con los recogidos aquí para la subespecie como, por ejemplo, el rizoma y el color de los dientes de las lígulas internas del capítulo, la mayoría sí son conformes.
2. Leontodon caroliaedoi Talavera \& M. Talavera, sp. nov.

Holotype: SPAIN. Puerto de Piqueras (Logroño, España), 12 km NE del Puerto, pinar aclarado en substrato silíceo, $42^{\circ} 04^{\prime} 012 \mathrm{~N}$ 02 31'002W, $1680 \mathrm{~m}, 12$.VIII.2004, Carlos Aedo legit, no 10465 (MA-719016a; MA-719016 b-e, isotypes).

Perennial plants $12-15 \mathrm{~cm}$ tall, with one to many well-developed stems, rhizomatose, strigose; rhizome 4-6(-8) $\mathrm{mm}$ in diameter, vertical, much branched at the apex with many persistent remnants from previous flowerings, with roots that are fibrous almost throughout their length. Stems spreading, unbranched frequently with 1-2 bracts in the upper third, laxly villous in the lower half, with most hairs bifid of 0.3-0.7 mm, mostly glabrous above. Leaves 2-5.5 cm, narrowly elliptic, pinnatifid or pinnatisect, strigose, with all hairs 0.2-0.7 mm, 2-3-fid more densely present on the lower surface, especially around the central nerve; Capitula solitary. Involucre 8-12 x 5-7 $\mathrm{mm}$, subcylindrical or campanulate, with 2-3 series of bracts; bracts narrowly lanceolate or linear-elliptic, with the outer surface laxly covered with mostly bifid setiform hairs of 0,8-2 mm, especially near the median nerve, and with many short spidery hairs at the base. External flowers of the capitulum 13-15 mm, yellow, with a broad purple band on the exterior, the innermost flowers completely yellow; anthers 1,9-2,2 mm, yellow; stylar branches 1-1,2 mm, yellow. Achenes homomorphic, 5,5-7 x 0,5-0,7 mm, more or less cylindrical, without a beak, the most external more or less incurved, the innermost straight, with 5-10 longitudinal ribs, with weakly developed transverse scales, lacking spicules, glabrous, brown or reddish-brown. Pappus 6-7 mm, white and persistent, with the hairs and scales disposed in three rows, the most external of scabrid hairs of 0,5-0,7 $\mathrm{mm}$, the rest formed of 


\section{8-20 plumose scales.}

Hierba perenne, caulescente, rosulada, unio pluricaule, rizomatosa, estrigosa, con pelos 2-3-fidos, en los tallos y hojas con pedículo de $0,2-0,7 \mathrm{~mm}$ y brazos \pm patentes de $0,1-0,2 \mathrm{~mm}$, $\mathrm{y}$ en el dorso de las brácteas del involucro con pedículo de 0,8-2 mm y los brazos, normalmente desiguales, de c. 0,1 mm; rizoma de 4-6(8) $\mathrm{mm}$ de diámetro, vertical, muy ramificado en el ápice, con numerosos restos de hojas de floraciones anteriores, con raíces fibrosas en casi toda su longitud. Tallos 1,2-1,5 x 0,6-0,8 $\mathrm{mm}$ de diámetro en la base, \pm cilíndricos, hasta de 1,2 mm de diámetro junto al capítulo, acostillados longitudinalmente, escapiformes, simples, casi siempre con 1-2 brácteas en el tercio superior, laxamente vilosos en la mitad inferior, con la mayoría de los pelos de 0,3-0,7 $\mathrm{mm}$, bífidos, por lo general glabros en la parte superior. Hojas 2-5,5 x 0,5-1 cm, estrechamente elípticas, pinnatífidas o pinnatisectas, atenuadas hacia la base en un pecíolo más corto que el limbo, estrecho, verdoso o rojizo, estrigosas, con todos los pelos 2-3-fidos, pediculados, con los pedículos de 0,2-0,7 mm, más densamente dispuestos en el envés, sobre todo cerca del nervio medio. Capítulos solitarios, péndulos antes de la antesis, erectos en la madurez. Involucro 8-12 x 5-7 mm, subcilíndrico o campanulado, con 2-3 series de brácteas, las externas más pequeñas que las internas; brácteas estrechamente lanceoladas o linearelípticas, cilioladas en el ápice, con el dorso laxamente cubierto de pelos setiformes de 0,8-2 $\mathrm{mm}$, la mayoría bífidos, sobre todo cerca del nervio medio, junto a numerosos pelos cortos y araneosos en la base, las externas 2-3 x 0,6-0,9 $\mathrm{mm}$, linear-lanceoladas, las internas 9-10 x 1,5-1,7 mm, linear-elípticas. Receptáculo alveolado, plano, con los alvéolos rodeados de una corona escariosa estrecha, glabro. Corola de las flores más externas del capítulo de 13-15 mm, amarilla, con una banda purpúrea y ancha en el dorso, en las centrales del capítulo completamente amarillas; tubo 4-5 mm, glabro o con algún que otro pelo en el ápice; limbo 8-9 mm, laxamente viloso en la base. Anteras 1,9-2,2 mm, amarillas. Ramas estilares 1-1,2 $\mathrm{mm}$, amarillas. Aquenios homomorfos, de 5,5-7 x 0,5-0,7 mm, \pm cilíndricos, sin pico, los más externos del capítulo \pm incurvos, los internos rectos, con 5-10 costillas longitudinales, con escuámulas transversales débilmente desarrolladas, sin espículos, glabros, pardos o pardo-rojizos, con vilano. Vilano $6-7 \mathrm{~mm}$, blanco, persistente, con pelos y escamas dispuestos en 3 filas, la fila más externa de pelos escábridos de 0,5-0,7 mm, las demás con 18-20 escamas plumosas, las medias de menor tamaño que las internas.

\section{Ecología, fenología y distribución}

Pinares aclarados, en substratos silíceos; c. 1680 m. VII-VIII. Endemismo de la Península Ibérica. Norte de España, en las inmediaciones del Puerto de Piqueras. Esp.: Lo.

3. Leontodon boryi Boiss. ex DC., Prodr. 7: 103 (1838)

$\equiv$ Apargia hispida Bory in Ann. Sci. Phys. 3: 5 (1820), nom. nudum.

Ind. loc.: "in campis aridis Sierrae Nevadae regni Granatensis ad altit. 6700-9500 ped. (Boiss.!)".

Lectotipo: designado por Burdet et al. (1983; G-DC).

\section{Ecología, fenología y distribución}

Pedregales y gleras, en micaesquistos; (1800)2200-3000 m. (VI)VII-VIII. Endemismo del sur de España: Sierra Nevada y Sierra de los Filabres. Esp.: Al Gr.

\section{Observaciones}

L. boryi es una planta que produce muy pocas semillas, posiblemente por una fuerte autoincompatibilidad, que compensa por multiplicación vegetativa. Desde el punto de vista morfológico la especie es parecida a $L$. 
pitardii Maire in Bull. Soc. Hist. Nat. Afrique N 15: 105 (1924), del Atlas marroquí, pero esta última tiene hojas mucho más pequeñas que los tallos y éstos son rectos y rígidos, con pubescencia muy pequeña, sin pelos rígidos, las brácteas del involucro son lanceoladas, y flores más pequeñas, con los dientes de las lígulas internas del capítulo rojizos y el vilano con c. 20 escamas plumosas largas.

\section{Leontodon farinosus Merino \& Pau in} Merino, Fl. Galicia 2: 452 (1906)

- L. graecus sensu Merino, Contr. Fl. Galicia Supl. IV: 26 (1904), non Boiss. \& Heldr.

Ind. loc.: "Vive en las inmediaciones del bosque de La Rogueira, Courel, al lado de la aldea de Moreda, Lugo. Fl. en principios de verano (V.vivum Fruct.)"'.

Lectotipo (designado aquí): Etiqueta 1. "1762 / Leontodon crispus Vill. / en la montaña de Nogueira (Lugo). Nueva para / la flora española / leg. P. Merino 1901 [manuscr. B. Merino] / 8332 [manuscr. C. Pau] ". Etiqueta 2. "Real Jardín Botánico, Madrid / Leontodon farinosus Pau \& Merino in Merino /Revisado / A. Izuzquiza 1-1989” (MAF-13390)].

\section{Ecología, fenología y distribución}

Fisurícola, en roquedos calcáreos o dolomíticos, rara vez pizarras; (420)600-2000 m. (V)VI-VIII. Endemismo del NW de España: Montes de León y Caurel, y estribaciones más occidentales de la Cordillera Cantábrica. Esp.: Le Lu Or.

\section{Observaciones}

Especie parecida a Leontodon crispus L., pero en L. crispus la mayoría de los pelos de las hojas tienen un pedículo de 0,5-1 $\mathrm{mm}$.

En el herbario del Real Jardín Botánico de Madrid existe un pliego (MA-137954) de Leontodon farinosus en cuya etiqueta figura "Leontodon crispus Vill. / En la cumbre de la Nogueira (Caruel, Lugo)" con letra de Baltasar
Merino. En este pliego existe, además, otra etiqueta de A. Izuzquiza en la que se indica que esta planta es el lectotipo de L. farinosus. Evidentemente, la identidad de la planta contenida en el pliego es incuestionable, pero no hay ninguna otra indicación que permita asegurar que esa planta fue recolectada antes de la publicación del nombre. Por este motivo, se ha preferido elegir como lectotipo el pliego conservado en el herbario de la Facultad de Farmacia de la Universidad Complutense de Madrid (MAF-13390), en el cual figura la fecha de recolección de la planta por el Padre Merino. El material tipo lo compone una planta casi completa, con un solo escapo y el capítulo en fructificación, además de algunas hojas sueltas. Todos los caracteres de esta planta coinciden con la descripción original de L. farinosus.

5. Leontodon crispus Vill., Prosp. Hist. Pl. Dauphiné: 34 (1779)

Ind. loc.: No indicada de forma expresa [Dauphiné, Francia].

Lectotipo (designado aquí): "N. / Leontodon crispum N. [manuscrito Villars] / des alpes voisines de grenoble. M. Villar. 1780 [manuscrito?]" (MPU-023657).

= Crepis nudicaulis L., Sp. Pl.: 805 (1753) $\equiv$ Leontodon nudicaulis (L.) Schinz \& Thell. in Bull. Herb. Boissier, ser. 2, 7: 387 (1907), nom. illeg., non Lag. ex Merat (1831) = Apargia saxatilis Ten., Cat. Hort. Neapol. 1813, App. 1, ed. 2: 59 (1819)

$\equiv$ Leontodon saxatilis (Ten.) Rchb., Fl. Germ. Excurs.: 252 (1831-1832), non Lam. (1779)

$\equiv$ Leontodon crispus subsp. saxatilis (Ten.) Nyman, Consp. Fl. Eur.: 468 (1879)

$=$ Leontodon autranii Chabert in Bull. Herb. Boissier 4: 360 (1896)

Ecología, fenología y distribución

En fisuras de rocas calcáreas; 800-850 m. 
VI-VII. Regiones costeras de la cuenca $\mathrm{N}$ de la Región Mediterránea, desde España a Grecia. NE de España: Sierra de Montsant. Esp.: T.

\section{Observaciones}

En el herbario de Montpellier existe un pliego formado por tres plantas y dos etiquetas. A la etiqueta 1, en la que se lee "N. / Leontodon crispum N. [manuscrito Villars]" y pegada a ella se indica / "des alpes voisines de grenoble. M. Villar. 1780 [manuscrito?] (MPU-023657)", esta doble etiqueta se asocia a una planta de unos $25 \mathrm{~cm}$, con tres escapos y sus respectivos capítulos, dos de ellos en fruto y uno ya dispersado. Por otro lado, la etiqueta 2, en la que se lee "Leontodon / de M. Villar / H.R.P. 1782 (MPU-023658)", está pegada sobre una planta de unos $20 \mathrm{~cm}$, con dos capítulos, uno en fruto $\mathrm{y}$ otro en flor, pero es evidente que la planta procede de cultivos y probablemente posterior a la descripción de la especie. Consecuentemente, se elige como lectotipo el ejemplar del pliego MPU-023657, en cuya etiqueta se indica que se trata de una especie nueva, y la grafía es claramente de Villars. La procedencia de la planta y la fecha que figura bajo el nombre tiene una grafía distinta a la de Villars, por lo que suponemos que es de alguna persona relacionada con Villars, y la fecha que figura es el año en que llegó la planta al herbario.

Cuando Linneo describió Crepis nudicaulis L., Sp. Pl.: 805 (1753) [三Leontodon nudicaulis (L.) Schinz \& Thell. in Bull. Herb. Boissier, ser. 2, 7: 387 (1907), nom. illeg., non Lag. ex Mérat (1831); 三 Thrincia nudicaulis (L.) Britten in J. Bot. 45: 33 (1907), nom. illeg., non Lowe (1831); 三Virea nudicaulis (L.) House in Bull. New York State Mus. Nat. Hist. 243-244: 69 (1923)], indicó en el protólogo "Habitat in G. Narbonensi, Hispania”. En los herbarios que este autor utilizó no existe ningún pliego con dicha denominación Crepis nudicaulis, lo que ya fue puesto en evidencia por Lacaita (1918). Por ello, Rauchert (1977) eligió como lectotipo el icón "Hieracium denti leonis folio hirsutie asperum minus" de C. Bauhin, Prodr. Teatri Bot.: 63 (1620), sinónimo utilizado por Linneo cuando describió Crepis nudicaulis. Bauhin, al describir su especie indicó que las hojas tienen pelos 1-3-fidos "...folia ad radicem pilosa, aspera, angusta, uncias duas longa, ..., asperi, modo unos, modo bini, ternive..." e indicó como lugar de procedencia de la planta descrita: "Monspessuli provenit. ...ex Hispania D. Albinus". A juzgar por el icono, y por la descripción del indumento foliar, la planta iconografiada bien podría corresponder a Crepis nudicaulis L., como ya indicó Lacaita (1918), y no a L. hirtus L., como otros autores señalaron (Britten, 1907; Schinz \& Thellung, 1907). De todas formas, el binomen Crepis nudicaulis no puede usarse dentro de Leontodon ya que Mérat (1931) había descrito Leontodon nudicaulis Lag. ex Mérat, un sinónimo de Thrincia hispida, que nada tiene que ver con la planta de Linneo.

\section{Taxones probables}

Leontodon hirtus L., Syst. Nat., ed. 10: 1194 (1759) [= Apargia villarsii Will., Sp. Pl. 3: 1552 (1804); 三Leontodon villarsii (Willd.) Loisel., Fl. Gall.: 514 (1807)] fue indicado de España [cf. Linneo, Sp. Pl., ed. 2, 2: 1552 (1763)]. Esta especie está basada en la var. $\beta$ y $\gamma$ de Leontodon hispidus L., Sp. Pl.: 799 (1753). Los únicos elementos descriptivos para la var. $\beta$ son: "Hieracium, dentis leonis folio, hirsutie asperum minus laciniatum. Bauh. pin. 127. prodr. 63", y para la var. $\gamma$ también dos nombres frase, uno de Bauhin, "Hieracium, dentis leonis folio, hirsutie asperum magis laciniatum. Bauh. pin. 127", y el otro de Bauhin y Cherler: "Hieracium parvum hirtum, caule aphyllo, crispum ubi siccatum. Bauh. hist. 1038". Por consiguiente, el tipo se debería encontrar entre el material del herbario de Burser, que contiene los materiales de Bauhin y que fueron estudiados por Linneo, o en alguna iconografía citada en las obras de Bauhin. Efectivamente, en 
el herbario de Burser existe un pliego (VI: 47) con una sola planta, pequeña, que identificamos como L. hirtus L., y en la iconografía de Bauhin \& Cherler, Hist. Pl. Univ. 2: 1038 (1651), existe un icono bajo el nombre "Hieracium parvuum hirtum caule aphyllo, crispum ubi siccatum" que representa muy fielmente una planta en flor de Leontodon hirtus L. Entre los dos elementos de que disponemos para la tipificación, se elige como lectotipo la planta conservada en el herbario de Burser (Herb. Burser VI: 47).

L. hirtus L. es una planta pequeña, menor de $20 \mathrm{~cm}$, con tallos cilíndricos, glabros, con varias brácteas repartidas por casi toda su longitud. Tiene hojas pinnatífidas, con los lóbulos elíptico-lanceolados, el terminal no mucho mayor que los laterales, muy hirsutas, con pelos escábridos de 1-2(2,5) mm, gruesos, escábridos y blancos, algunos simples, indivisos, pero muchos de ellos bífidos o subbífidos, con los brazos erecto-patentes menores de $0,1 \mathrm{~mm}$; capítulos con involucro de 10-11 x 10-11 mm, campanulado, con 3 series de brácteas araneosas junto con pelos rígidos aculeiformes de 0,5-1,3 $\mathrm{mm}$, concentrados en la quilla del nervio medio del dorso; flores más externas del capítulo con corola de 8-9 mm, amarilla, concolora; anteras c. 3,2 $\mathrm{mm}$; ramas estilares c. 1,3 $\mathrm{mm}$; aquenios 6-6,5 x 0,5-0,7 mm, subcilíndricos, sin pico, con escuámulas erosas transversales \pm marcadas, parduscos, con vilano de 6-6,5 mm, constituido por 17-18 escamas plumosas que alternan con pelos escábridos, más delgados y más cortos que las escamas.

Bolòs y Vigo (1995: 972) citaron esta especie del Pirineo Oriental [Fenollada, Conflent y Vallespir (Francia)], pero entre el material de herbario estudiado para la síntesis taxonómica del género Leontodon para Flora iberica, no se ha encontrado ningún pliego que respalde su presencia en España. Tan solo en el Herbario de la Universidad Complutense de Madrid existe un pliego (MAF13512), con dos plantas de L. hirtus L., supuestamente recolectadas en el Pirineo Central por Marcelo Rivas
Mateos. Es más que dudosa esta procedencia, pero dado que la especie se encuentra en la vertiente francesa de los Pirineos, bien se podría encontrar en la española, donde no obstante sería extraordinariamente rara, como lo es también L. crispus en el NE de España.

\section{Taxones a excluir}

Leontodon pavonii Boiss., Diagn. P1. Orient., ser. 2, 3: 87 (1856) fue descrito de un material procedente del herbario de Pavón y recolectado en los "Altos de La Moral", adyacentes a Salamanca, el día 16 de septiembre de 1806. Dicho material tipo se conserva en el herbario del Conservatorio y Jardín Botánico de Ginebra (G00300113; visto en fotografía), y está formado por la base de una planta con rizoma vertical, largo y \pm leñoso, con una roseta de hojas pinnatífidas o pinnatipartidas, y de un tallo monocéfalo en floración segregado. Según las observaciones del conservador del herbario, las hojas tienen pelos simples y el vilano es plumoso, pero en el ovario se observa un pico incipiente. Probablemente, la base de la planta puede pertenecer a una especie del género Crepis, tal vez $C$. albida, y el tallo monocéfalo a Hypochaeris radicata L. En el pliego aparece una etiqueta de Widder (III-1993) que indica "Not est Leontodon!", y otra de E. Beauverd de 1924 donde escribe, entre otras cosas: “... Hypochaeris cf. radicata!".

AGRADECIMIENTOS. Agradecemos al editor de esta serie en Acta Botanica Malacitana por sus comentarios y correcciones, a los conservadores de los herbarios que nos enviaron los materiales que figuran en el texto, a Pilar Fernández-Piedra y al Dr. Fco. Javier Salgueiro por la búsqueda bibliográfica, y al Dr. Peter Gibbs por su ayuda para los textos en inglés.

\section{BIBLIOGRAFÍA}

BATTAGLIA, E. -1951- Development of angiosperm 
embryo sacs with non-haploid eggs. Am. J. Bot. 38: 718-724.

BERGMAN, B. -1935- Zytologische Studien über die Fortpflanzung bei den Gattungen Leontodon und Picris. Svensk Bot. Tidskr. 29: 155-301.

BOLÒS, O. DE \& J. VIGO -1995- Flora dels Països Catalans, 3. Editorial Barceno. Barcelona.

BRITTEN J. -1907- Thrincia nudicaulis. J. Bot. 45: 31-33.

BURDET, H. M.,A.CHARPIN \& F. JACQUEMOUD -1983- Types nomenclaturaux des taxa ibériques décrits par Boissier ou Reuter. IV. Cistacées à Composées. Candollea 38: 751-802.

ENKE, N., B. GEMEINHOLZER \& C. ZIDORN -2012- Molecular and phytochemical systematics of the subtribe Hypochaeridinae (Asteraceae, Cichorieae). Org. Divers. Evol. 12: 1-16.

FINCH, R. A. \& P. D. SELL -1976- Leontodon. In Tutin T.G, V.H. Heywood, N.A. Burges, D.M. Moore, D.H. Valentine, S.M. Walters \& D.A. Webb (eds.). Flora Europaea 4: 314. Cambridge University Press. Cambridge.

GREEN, M. L. -1929- The application of "nomina generica conservanda" to be determined by means of specified Standard-Species pp. 97-109, IN: International Botanical Congress Cambridge (England), 1930. Nomenclature. Proposal by British Botanists (Prop. Brit. Bot). London.

LACAITA, C. C. -1918- Crepis nudicaulis L. and Leontodon hirtus L. J. Bot. 56: 97-105.

MÉRAT, D. M. -1931- Examen des genres Apargia et Thrincia, avec la description abrégée des espèces à feuilles hispides placées dans ces deux genres. Ann. Sci. Nat. (Paris) 22: 101-112 (1931).

PAU, C. -1925- Correrías Botánicas. Bol. Soc. Iber. Ci. Nat. 23: 89-105

PITTONI, E. -1973- Leontodon L. In: K. H. Rechinger -ed.- Flora Iranica 122: 128 -130. K. H. Rechiger. Vienne (Austria).

RAUCHERT, S. -1977- Nomenklator der Farn-und Blütenflanzen Deutshland (V). Feddes Repert. 88: 307-321.

RIVAS MARTÍNEZ, S. \& C. SÁEZ -1980- Sobre Leontodon bourgaeanus Willk. (Asteraceae). Anales Jard. Bot. Madrid 35: 155-157.
SCHINZ, H. \& A. THELLUNG -1907- Begründeung vorzunehmender Names"nderungen an der sweiten Auflage der $<<$ Flora der Schweiz $>>$ von Schinz und Keller. Bull. Herb. Boissier, sér. 2, 7: 387-390.

Dirección de los autores. Departamento de Biología Vegetal y Ecología (Botánica). Facultad de Biología, apartado 1095. 41080-Sevilla. *Autor para correspondencia: mtalavera@us.es 